\title{
European comparisons between mental health services
}

\author{
K. Wahlbeck*
}

When developing accessible, affordable and effective mental health systems, exchange of data between countries is an important moving force towards better mental health care. Unfortunately, health information systems in most countries are weak in the field of mental health, and comparability of data is low.

Special international data collection exercises, such as the World Health Organization (WHO) Atlas Project and the WHO Baseline Project have provided valuable insights in the state of mental health systems in countries, but such single-standing data collections are not sustainable solutions. Improvements in routine data collection are urgently needed. The European Commission has initiated major improvements to ensure harmonized and comprehensive health data collection, by introducing the European Community Health Indicators set and the European Health Interview Survey. However, both of these initiatives lack strength in the field of mental health. The neglect of the need for relevant and valid comparable data on mental health systems is in conflict with the importance of mental health for European countries and the objectives of the 'Europe 2020' strategy.

The need for valid and comparable mental health services data is today addressed only by single initiatives, such as the Organisation for Economic Co-operation and Development work to establish quality indicators for mental health care. Real leadership in developing harmonized mental health data across Europe is lacking. A European Mental Health Observatory is urgently needed to lead development and implementation of monitoring of mental health and mental health service provision in Europe.

Key words: mental health services, international comparison, health service indicators, Europe.

Service users, policy makers and the general public increasingly demand that mental health systems should provide good 'value for money'. Thus, there is a growing interest for benchmarking mental health systems and their outcomes across countries. In Europe, mental health systems vary widely from country to country (WHO Regional Office for Europe, 2008), causing considerable challenges to comparison and benchmarking efforts. Considerable variation exists not only between countries, but also within countries between regions and local communities, and at all levels of the mental health service system: health legislation and policy, funding arrangements, organisation of care provision and even in clinical practice.

On the policy level, in 2005 a common mental health strategy for the World Health Organization (WHO) European Region was formulated in the Declaration and Mental Health Action Plan for Europe, undersigned by representatives of all European countries (WHO Regional Office for Europe, 2005). The core of the service provision strategy is to ensure good access to mental health care by building up the capacity and

* Address for correspondence: Kristian Wahlbeck, Department of Mental Health and Substance Abuse Services, National Institute for Health and Welfare, P.O. Box 30, FIN-00271 Helsinki, Finland.

(Email: kristian.wahlbeck@thl.fi) ability of general practitioners and primary care services to offer identification and effective pharmacological and psychotherapeutic treatments to people with mental health problems. Furthermore, the health policy of European countries encompasses major reform of specialised mental health services, moving from large institutions to community-based care supported by psychiatric beds in general hospitals.

To achieve these pan-European strategic objectives, reliable data on mental health services and trends in mental health service provision are needed. International benchmarking, based on comparable data, is an important moving force for development of mental health services in countries. Unfortunately, mental health information systems in most countries are geared towards hospital data, which are of less interest when developing a community-based mental health service provision system. Many highly relevant aspects of modern service provision, such as patient choice, service user empowerment and respect for human rights, are hardly ever covered by health information systems.

In view of the shortcomings of routinely collected data, special data collections have been implemented to retrieve information on mental health systems. The WHO Atlas Project is an impressive ongoing effort to collect comparable data on a global level, including Europe. Currently, worldwide data collection is 
being undertaken for a third edition to follow the previous editions of the Mental Health Atlas (WHO, 2001; WHO, 2005).

On the European level, a first special data collection was the WHO Baseline Project in 2007 (WHO Regional Office for Europe, 2008). It provided the first comprehensive cross-sectional snapshot of mental health services in the WHO European Region. The data collection evidenced that in a majority of countries, general practitioners already have a role in identifying, diagnosing and treating people with mental health problems, the role being less prominent for severe mental disorders and in the eastern countries. It also demonstrates an extreme variation in the total number of psychiatric beds per capita in Europe, from 185 beds per 100000 population in Malta to 8 beds per 100000 in Italy. In some countries, a low number of beds indicates successful deinstitutionalisation and availability of community care (e.g. Italy), in other cases a low number of psychiatric beds (for instance 12 beds per 100000 population in Turkey) may indicate low investment in mental health care and reliance on families instead of formal care. In spite of attempts to standardise terminology, comparability between countries is not always high, due to differing interpretations of the definitions. Data were collected on a coarse national level only, which complicates interpretation of findings especially from countries where mental health services are organised on a regional or local level.

Comparable data and standardised definitions are prerequisites for reliable European comparative mental health services research. Indeed, comparisons based on disparate and non-harmonized data may cause more confusion than clarification (Ekholm \& Bronnum-Hansen, 2009). Today, several sources of incomparability in routine collection of mental health services data hamper European comparisons. Such sources of bias in existing European health information databases include differences in recruitment to services due to country-specific share of work between health and social services, differing registration practices regarding for instance intra-hospital transfers, leave days and day hospital episodes, as well as national peculiarities in diagnostic practice (Katschnig et al. 2006).

In spite of the existing challenges, considerable advances have been made to harmonize mental health services data by the European Commission, intergovernmental agencies, research teams and individual researchers. The European Service Mapping Schedule (ESMS) (Johnson \& Kuhlmann, 2000) provides a new basis for a common classification of mental health services. The ESMS has been used for comparison across countries in Europe, for instance, in the European
Psychiatric Services: Inputs Linked to Outcome Domains and Needs (EPSILON) study (Becker et al. 2002). Mental health service use in Europe has been mapped by the European study of the Epidemiology of Mental Disorders (ESEMeD) study, albeit in a restricted set of countries (Alonso et al. 2004). These and other research efforts have contributed to filling vast gaps in our knowledge about mental health services in a European perspective.

In order to improve health data harmonization, WHO, the statistical office of the European Union (EU) Eurostat and the Organisation for Economic Co-operation and Development (OECD) have, during the recent years, harmonized their definitions on health systems data. Since 2010, the organisations jointly collect data on health systems (manpower, hospital beds and medical technology) from member countries by a joint questionnaire. The joint work has resulted in, among others, common definitions for 'psychiatrists' and 'psychiatric beds' (Eurostat, 2010).

Furthermore, OECD has initiated work to establish common mental health-care quality indicators (Hermann et al. 2004; Armesto et al. 2008). In 2009, the first results were published for the quality indicators readmission rate in schizophrenia and bipolar disorder. Unplanned hospital readmission rates may indicate poor care coordination following a hospital stay for psychiatric disorders. The results showed widespread and largely unexplained variations between OECD countries in hospital readmissions for bipolar disorder and schizophrenia (OECD, 2009). The Nordic countries evidenced the highest rate of unplanned readmissions to psychiatric care. This example illustrates one of the problems of making international comparisons of care quality, i.e. differences in documentation systems. For example, Nordic countries are able to track patients across care settings using unique patient identifiers and so are better able to identify readmissions than many other countries.

The European Commission has initiated an ambitious programme to improve and harmonize health data collection in the EU. The starting point is the European Community Health Indicators (ECHI) shortlist (Kramers, 2003), now comprising 88 health indicators (Kilpeläinen et al. 2008). These include 30 harmonized indicators of health services, but regrettably very few of them are of relevance for mental health services, and none of them covers the aspects that are crucial in modern mental health care: service provision in primary care and community-based mental health care.

It is envisaged that in the future a repeated European Health Interview Survey (EHIS) and European Health Examination Survey (EHES) will 
constitute the major sources of comparable health information on the ECHI. Work to develop mental health indicators for the ECHI system has been undertaken (Korkeila et al. 2003; Wahlbeck, 2007), leading to a proposed set of 35 indicators. Of these, 17 are mental health systems indicators, covering mental health system resources, mental health-care utilisation and expenditure on mental health services (Lavikainen et al. 2006). An analysis of availability of the proposed mental health indicators demonstrated that data on psychiatric hospital use are available to a reasonable extent across EU countries, but also showed that huge information gaps exist, notably in the areas of community-based mental health services and mental health expenditure (Wahlbeck, 2006).

The EHIS consists of four core modules, covering background variables, health determinants, health status and health care, constituting altogether about 130 questions. A first survey wave was implemented in 2007-2009 in 21 countries, and a second wave is planned for 2014. Unfortunately, mental health was not well covered in the first EHIS wave, and also the survey questions used need improvement as well as linguistic and cultural validation.

It can be concluded that the health information system currently being initiated by the European Commission is not strong in the field of mental health, neither in the set of approved indicators (ECHI), nor in the survey-based data collection (EHIS). The weakness of the system in the field of mental health is in cutting conflict with the increasing importance of mental health for the 'Europe 2020' strategic objectives of the EU and with the policy priority of mental health services in many member states. A smart, sustainable and inclusive growth cannot be achieved in the EU without good population mental health. Population-level mental health actions require a wellfunctioning mental health monitoring system. This fact is largely ignored by the current plans for improving health information systems in the EU.

It is evident that an intensive and widespread work to harmonize health indicators and improve data comparability is being undertaken. This work will lead to improved statistical data in the main databases providing international data (i.e. the WHO 'Health for All' database, the Eurostat public health data and the OECD health data) and enhanced health survey data quality due to harmonization of health interview and health examination surveys. The ECHI system and the OECD system of health accounts provide a basis for common definitions of individual- and systemlevel health indicators. However, much of the development work neglects the need for improvements in the relevance, availability and quality of information on mental health systems. There is a major discrepancy between the importance of mental health services, and efforts to develop, collect and analyse comparable international data on mental health care. Single exceptions exist: OECD work has produced proposals for common quality indicators for mental health services. A further step in comparing European mental health services data will be taken when the 'Financing systems' effects on the Quality of Mental health care in Europe (REFINEMENT)' project will take off in 2011. This project, co-ordinated by University of Verona, will be a first ever attempt to analyse links between the financing of mental health care in Europe and the outcomes of mental health services in the nine participating countries.

The need for reliable and comparable data creates a need for a 'European Mental Health Observatory' to establish leadership in mental health monitoring in Europe. Such an observatory should be linked to the WHO Regional Office and the European Center for Disease Control. Such an Observatory could be built according to the model of the European Monitoring Centre for Drug and Alcohol Abuse (EMCDDA), which has successfully developed and implemented monitoring of drug abuse. Mental health issues, which are often neglected and forgotten due to lack of awareness and stigma, need strong European institutions. A European Mental Health Observatory could be such a strong institution and a flagship for promoting awareness about the importance of mental health and mental health care.

\section{Declaration of interest}

None.

\section{References}

Alonso J, Angermeyer MC, Bernert S, Bruffaerts R, Brugha TS, Bryson H, de GG, Graaf R, Demyttenaere K, Gasquet I, Haro JM, Katz SJ, Kessler RC, Kovess V, Lepine JP, Ormel J, Polidori G, Russo LJ, Vilagut G, Almansa J, rbabzadeh-Bouchez S, Autonell J, Bernal M, Buist-Bouwman MA, Codony M, Domingo-Salvany A, Ferrer M, Joo SS, Martinez-Alonso M, Matschinger $\mathrm{H}$, Mazzi F, Morgan Z, Morosini P, Palacin C, Romera B, Taub N, Vollebergh WA (2004). Use of mental health services in Europe: results from the European study of the Epidemiology of Mental Disorders (ESEMeD) project. Acta Psychiatrica Scandinavica. Supplementum 420, 47-54.

Armesto SG, Medeiros H, Wei L (2008). Information Availability for Measuring and Comparing Quality of Mental Health Care Across OECD Countries. OECD Health technical papers 20. OECD: Paris (http://www.oecd.org/dataoecd/53/ 47/41243838.pdf).

Becker T, Hulsmann S, Knudsen HC, Martiny K, Amaddeo F, Herran A, Knapp M, Schene AH, Tansella M, 
Thornicroft G, Vazquez-Barquero JL (2002). Provision of services for people with schizophrenia in five European regions. Social Psychiatry and Psychiatric Epidemiology 37, 465-474.

Ekholm O, Bronnum-Hansen H (2009). Cross-national comparisons of non-harmonized indicators may lead to more confusion than clarification. Scandinavian Journal of Public Health 37, 661-663.

Eurostat (2010). Definitions and Data Collection Specifications on Health Care Statistics (Non-Expenditure Data). Version 19 July 2010. European Commission: Luxembourg (http://circa. europa.eu/Public/irc/dsis/health/library?l = /methodologies sandsdatasc/health_care/estat-oecd-definitions-c/_EN_1. $\left.0 \_\& a=i\right)$.

Hermann R, Mattke S, OECD Mental Health Care Panel (2004). Selecting Indicators for the Quality of Mental Health Care at the Health Systems Level in Oecd Countries. OECD Health technical papers 17. OECD: Paris (http://www.oecd. org/dataoecd/28/32/33865630.pdf).

Johnson S, Kuhlmann R (2000). The European Service Mapping Schedule (ESMS): development of an instrument for the desription and classification of mental health services. Acta Psychiatrica Scandinavica. Supplementum 405, 14-23.

Katschnig H, Breier P, Constantopoulos A, Dragomirecka E, Rancans E, Reneses B, Angerer K, Obernosterer E (2006). Monitoring service utilisation. In Improving Mental Health Information in Europe (ed. J Lavikainen, T Fryers and V Lehtinen), pp. 67-77. STAKES: Helsinki (http://www. stakes.fi/pdf/mentalhealth/Mindful_verkkoversio.pdf).

Kilpeläinen K, Aromaa A, ECHIM Core Group (ed.) (2008). European Health Indicators: Development and Initial Implementation (Final Report of the ECHIM Project. Publications of the National Public Health Institute B 31/ 2008). National Public Health Institute: Helsinki (http:// www.echim.org/docs/ECHIM_final_report.pdf).
Korkeila J, Lehtinen V, Bijl R, Dalgard OS, Kovess V, Morgan A, Salize HJ (2003). Establishing a set of mental health indicators for Europe. Scandinavian Journal of Public Health 31, 451-459.

Kramers PG (2003). The ECHI project: health indicators for the European Community. European Journal of Public Health 13, 101-106.

Lavikainen J, Fryers T, Lehtinen V (ed.) (2006). Improving Mental Health Information in Europe. Proposal of the MINDFUL Project. STAKES: Helsinki (http://www.stakes.fi/ pdf/mentalhealth/Mindful_verkkoversio.pdf).

OECD (2009). OECD Health Care Quality Indicators Database.

Wahlbeck K (2006). Mental health in EU health monitoring systems. In Improving Mental Health Information in Europe (ed. J Lavikainen, T Fryers and V Lehtinen), pp. 117-128. STAKES: Helsinki (http://www.stakes.fi/pdf/mentalhealth/ Mindful_verkkoversio.pdf).

Wahlbeck K (2007). Recommendation on mental health monitoring for EU. European Psychiatry 22, I-III.

WHO Regional Office for Europe (2005). Mental Health: Facing the Challenges, Building Solutions: Report from the WHO European Ministerial Conference. World Health Organization Regional Office for Europe: Copenhagen. (http://www.euro.who.int/_data/assets/pdf_file/0008/ 96452/E87301.pdf).

WHO Regional Office for Europe (2008). Policies and Practices for Mental Health in Europe - Meeting the Challenges. World Health Organization: Copenhagen.

World Health Organization (WHO) (2001). Atlas. Mental Health Resources in the World 2001. World Health Organization: Geneva. (http://www.who.int/mental_health/ media/en/244.pdf).

World Health Organization (WHO) (2005). Mental Health Atlas 2005. Revised version. World Health Organization: Geneva. 